\title{
Perceptions regarding Distance Learning in Higher Education, Smoothing the Transition
}

\author{
Ardita Todri \\ Faculty of Economics, University of Elbasan "Aleksandër Xhuvani”, Albania \\ ORCID: 0000-0002-3825-0780 \\ Petraq Papajorgji \\ Faculty of Engineering, Canadian Institute of Technology, Albania \\ ORCID: 0000-0002-3833-5215 \\ Howard Moskowitz \\ Mind Genomics Associates, USA \\ ORCID: 0000-0002-7358-4348 \\ Francesco Scalera \\ Faculty of Economics, University of Bari "Aldo Moro", Italy \\ ORCID: 0000-0001-5566-4910
}

Received: 10 Jun 2020

Accepted: 4 Sep 2020

\begin{abstract}
This paper presents the perceptions on distance learning approaches, assessed through an online survey, using experimental design of ideas (Mind Genomics). Students and professors of higher education institutions who had not yet experienced distance learning before COVID-19 pandemic period participated in the study. The participants belong to the universities located in Mediterranean basin, e.g., Albania, Italy, Morocco, Algeria and few African countries.

Results suggest that distance learning will shift many of the responsibilities formerly on the professors to those of the students. The data suggests the need for emotional support during this transition, specifically to maintain interaction among students and professor as well as among students themselves in distance learning platforms as in traditional classrooms. The study shows that the effectiveness and the interactivity of this new paradigm are very important and any further developments of distance learning should provide strong support for these components. The position of the professor is indispensable as the guide to the entire process, suggesting that at least at the time of this writing (2020) distance learning approach is perceived only to be an intermittent complementary path to in-person interactions.
\end{abstract}

Keywords: distance learning, Mind Genomics, survey, user's perceptions

\section{INTRODUCTION}

The Distance Learning (DL), also referred to as distance education, e-learning, and online learning, represents an education approach which occurs when the professors and students are separated by space and time. DL is based upon the sophisticated technology of today which allows the participants to 'see' and 'hear' each other as if they were in the same room. The 'room' is the screen. Today's sophisticated technologies allow for these 'room's, and have become well know during the current (Spring 2020) COVID-19 crisis, which has forced the use of distance learning on the world of high education. 
With the advent of DL phenomenon, technology is entering yet in another aspect of our life; the one of education. Already social media is part of our everyday life and accompanying us anytime and everywhere we go through smartphones, tablets, etc. Although at the very beginning social media had only a social purpose, nowadays it is used for pleasure, business and sometimes even for education purposes as well. The world of the classroom is now the world of Blackboard, Canvas, Moodle, to name a just a few (Online Learning Statistics, 2019). DL as a model for education remains deeply influenced by the technology, especially digital developments.

DL appeared in the education market nearly two decades ago and it has had an important effect in the way we learn and think since. This industry has grown $900 \%$ since year 2000 and it is expected to triple its size from 2020 till 2025. The most serious efforts for implementing such a teaching platform were undertaken in Europe and USA that have $70 \%$ of the global market share (Online Learning Statistics, 2019).

During these pandemic times of COVID-19, institutions of higher education had to close their doors, to stop in-person teacher. In to keep educating, these institutions chose to use DL, and to continue educating. Most higher education institutions had not previously mastered the intricacies of DL, even though the COVID-19 crisis forces the paradigm shift with unexpected speed. Before the COVID-19 crisis, it could be said that DL played a supporting role; it has now assumed a central rule, and, in human relations terms, the faculty and the students are getting 'on the job training.'

The goal of the study is to understand what students and professors think about this approach, to have a feeling of the kinds of problems that are to be addressed so that the efficiency and the interactivity of the traditional teaching process are not negatively impacted. Four topics that could present an interesting 'story' about DL became the pillars of the study; effectiveness, interactivity, feasibility and the future of $D L$, respectively.

The 'freshness' of the paradigm shift, weeks and months, encouraged the study of these topics as perceived both by students and professors, two different worlds with direct, recent, and undoubtedly emotionallyimpact experience. The existing literature explored on the matter which addressed various aspects of DL such as users' barriers in the use of technology in higher education platforms (Jariang Pcasert, 2003; Nedelman, 2013); the evolution of technological institutional communication (Gutierrez et al., 2016); the student's skills and the intellectually-stimulating learning environment elements; distance learning platforms` typologies as well as the technological pedagogical approaches used (Alhih et al., 2017; Coymak, 2019). A key difference, beyond method, from previous studies is that this study involves people directly and immediately involved in the paradigm shift, as the shift actually occurs.

This study presents results obtained from a Mind Genomics experiment (Moskowitz et. al., 2006; Milutinovic \& Salom, 2017) with both students and professors of different group-ages, genders and stated reasons why distance learning is relevant to the respondents, i.e., the participants in the Mind Genomics experiment. The underlying theoretical framework is the narrative persuasion theory, which divides the message into logically different components; for whom; under what circumstances; how; and when does each message achieve optimum effect.

\section{Issues with DL at the Level of the University and its Culture}

Learning is an acquired skill, the most effective strategies vary from student to student (Brown et al., 2014). As of the last six months, the evolving paradigm of "Distance Learning" may be said to be the hallmark of today's higher education, today being literally today and just recently (Sun et al., 2007). In this context, the classrooms are represented in a larger framework. The 'new classroom' has been as is being designed both to deliver education, and to evaluate students who are the recipients of that education. The modality is the internet, an electronic, multi-media infrastructure, allowing a continual perspective on learning, comprehending, and mastering the material.

The sophistication and usability of the distance learning platforms varies among higher education institutions. As of this writing (Spring, 2020) there does not appear to be any defined framework and model 
for the use of $\mathrm{DL}$, or educational technology. The lack of a commonly agreed-to set of principles to guide the development of DL platform arises from the 'usual suspects,' namely management attitude, technical readiness, funding, and resources, etc. The list of that which is needed can be expanded to pages when the need becomes specific for a given group of professors and students, and the application specified in light of a specific university culture (Nedelman, 2013; Pcasert, 2003).

Beyond the general aspect of 'culture' of the specific institution of higher learning lies the very real aspect of structure and finances. Gutierrez et al., (2016) highlight other obstacles hindering the evolution of technological adoption in the institution. The strategy, or more appropriately the lack of strategy, the change in the nature of administrative costs, as well as the concomitant increase in the new cost to the institution of $\mathrm{DL}$, all become problems as the need for $\mathrm{DL}$ becomes increasingly real and immediate.

\section{Issues and Challenges with DL as a 'New' Learning Platform}

Beyond the university lies the standard problem confronting any new technology which moves from 'behind the curtain' to mainstream. DL is no exception. Continuing efforts are needed in order to improve the distance learning platforms new infrastructures such as acquisition, deployment, and maintenance of equipment. Funds must be allocated to the continuing evolution and improvement of the tools, and for the integration of new technologies such as the use of virtual and augmented reality based learning tools (Birch \& Barnett, 2009; Moro et al., 2017). The technology changes require that professors and students make the effort to attend training courses.

Beyond the training courses, however, is the active use of DL platforms. In the more conventional teaching mode, the student need only listen to the lecturer, take notes, and ask questions. DL requires more effort, and specifically, more focused effort. For example, Ossiannilsson (2012) and Ossiannilsson et al. (2015) reported that the effectiveness of distance learning platforms is gauged through the level of their interactivity, and not just by the ability of the lecturer to present a coherent lecture. New behaviors, attitudes, and skills are required from students in order to successfully complete the distance courses (Hart, 2014). These skills encourage them to adapt this new education paradigm with greater ease, i.e., less pain. At the same time, the burden for student interaction comes back to the nature of the course, how it is structured, and how well it is delivered, all the job of the lecturer (Robinson, 2009). Thus, it is both the higher education presenter, the lecturer, and the student, who, together, drive the effectiveness of the DL platform, a platform in the emerging "New Normal" in which successful business and social life require engaging intensive knowledge and constant learning (Coymak, 2019).

Considering the way of cooperating with students the distance learning platforms' of higher education institutions are grouped into two approaches: asynchronous and synchronous distance learning tools (Alhih et al., 2017). In the asynchronous group the content is constructed prior and stocked onto databases and only later on students can access it (Simonson \& Schlosser, 2009). The most popular variants used in these cases are the one of courses registered in CD-ROM, audio-visual presentations, audio power point slides, video-recorded courses, etc. Students using this distance learning version can explore even the forum, quizzes, messages and announcements practices. In such cases is recommended also the help of an online tutor for a successful comprehension of the presented topics. These types of distance learning platforms seem to be more flexible and fit better the lifestyle of students that work.

In the synchronous distance learning platforms instead, the professors and students cooperate simultaneously (Simonson \& Schlosser, 2009). This approach replicates the face to face communication style by using, audio and video conferences, and phone connections over the internet and live satellite broadcasts to communicate with the classroom. Thus, both professors and students provide a simultaneous feedback and discuss together as in a traditional classroom (Schwarz \& Asterhan, 2011). Later on, students can individually proceed to complete exercises or labs over the discussed topics. These kinds of distance learning platforms seem to be more useful for full time students.

In this rapid technology integration environment, little is explored concerning the ways in which structured distance learning materials help students to enhance the effectiveness of the used tools (Azevedo, 2005b; 
Ertmer, 2005). Regardless of the selected technology (in distance or face to face) the technological pedagogical content knowledge is a crucial element (Schmidt et al., 2009). The Schmidt et al., (2009) study defines the technological pedagogical content knowledge as the integrated knowledge required to combine technology and teaching within a specific subject and it constitutes an essential aspect even for pedagogical scientific research too. Koehler and Mishra (2009) see the technological pedagogical content knowledge as the knowledge covering changes that can occur in learning and teaching in certain situations by using certain technologies. Their study explains that the pedagogical process involves various advantages and disadvantages of technological instruments since they are associated with disciplinary and the development of the pedagogical designs and strategies.

Indeed, the understanding of the reasons related to technological pedagogical approaches itself can help higher education institutions students to be more flexible in this new digital era. At the same time, the acquired flexibility can be extremely helpful to students' future careers as well as to their academic achievement independently from the field of studies (Coymak, 2019).

In addition to the use of distance learning platforms students and professors prefer to exchange academic information even through social media. A number of studies (such as Al-Daboubi, 2014; Baishya \& Maheshwari, 2019; Mohamed \& Sumitha, 2011; Ruleman, 2012) show that in an increasing number students and professors use social media for academic purposes.

In this process both students and professors are mainly assisted by their mobile devices in order to communicate with each other. Baishya and Maheshwari (2019) show that an extended use of Whatsapp groups is also found effective for them for sharing information related to class, study materials, exams, grade distribution, etc. Other authors (such as Grosseck et al., 2011; Litchfield et al., 2007) found the use of Facebook mainly for sharing academic activities like: discussion about the assignment, lectures, class notes, research resource, etc. There are good reasons to believe that students and professors of higher education institutions behave proactively toward every type of computer/phone-mediated technologies for academic purposes.

This paper tries to contribute to the existing literature in three different ways. First, this study addresses the perception of students and professors using distance learning approach. To our knowledge, as of this writing (Spring, 2020), there is little in the way of understanding the mind of people involved in distance learning. Second, this study uses experimental design of ideas, Mind Genomics (Milutinovic \& Salom, 2017; Moskowitz et. al., 2006) to understand the minds of people with respect to specific messages. Mind Genomics, is a collection of well accepted yet novel approaches to understand the mind of the respondent. These methods begin with permuted experimental design; move on to dummy variable regression, clustering, and then creation of methods to assign a new person to one of the clusters or mind-sets uncovered. Third, the overarching goal of this paper is to present to higher education institutions some valuable findings and insights that deserve consideration when thinking about the need to improve distance learning at the practical level.

The rest of the paper is presented as follows: Section Methodology shows the data used for the analyses and the scientific approach, section Results and Discussions presents a list of the results obtained by this study, and the last section, Conclusions and Recommendations, shows findings of this study.

\section{METHODOLOGY}

\section{Participants and Settings}

An online survey was delivered to 6.672 students and professors inviting them to participate to the study. An international team of Albanians, Italians, Moroccans, Algerians and north African universities students and professors were selected provided they have not experienced distance learning before COVID-19 pandemic period. 
Table 1. The demographic characteristics of the participants

\begin{tabular}{|c|c|c|c|c|c|c|c|c|c|c|c|}
\hline \multirow[b]{2}{*}{$\begin{array}{l}\text { The demographic information of } \\
\text { the participants }\end{array}$} & \multirow[b]{2}{*}{ Total } & \multicolumn{2}{|c|}{ Gender } & \multicolumn{5}{|c|}{ Age } & \multicolumn{3}{|c|}{ Study Program } \\
\hline & & Male & Female & $13-17$ & $18-24$ & $25-34$ & $35-44$ & $45-54$ & +55 & Bachelor & Masters \\
\hline Base Size & 4.080 & 1.296 & 2.784 & - & 2.592 & 264 & 528 & 336 & 360 & 3.260 & 820 \\
\hline Albanian participants & 2.244 & 820 & 1.424 & - & 1.300 & 120 & 297 & 198 & 329 & 1.850 & 394 \\
\hline Italian participants & 1.020 & 200 & 820 & - & 732 & 40 & 158 & 90 & 0 & 735 & 285 \\
\hline Moroccan participants & 408 & 130 & 278 & - & 320 & 50 & 16 & 15 & 7 & 285 & 123 \\
\hline Algerian participants & 367 & 125 & 242 & - & 221 & 48 & 57 & 30 & 11 & 270 & 97 \\
\hline North African participants & 41 & 21 & 20 & - & 19 & 6 & 0 & 3 & 13 & 30 & 11 \\
\hline
\end{tabular}

Only 4.080 students and professors responded positively to the participation invitation from both public and private institutions and both programs: Bachelor and Masters. The participants in the survey correspond to: Albanians (55\%), Italians (25\%), Moroccans (10\%), Algerians (9\%) and north African (1\%) universities.

\section{Data Gathering}

Participants provided some personal data (see Table 1) such as gender, age, study program and indicated one of three reasons why they use distance learning as follows: Fast learning through tutorial services; Any time and everywhere learning; Learning while working.

Over $68.2 \%$ of the responders (students and professors) are female and around $31.8 \%$ are males. Over $63.5 \%$ of the responders were students in the age of $18-24$ years old and around $36.5 \%$ were professors. The professors in the age of 25-34 years old were around $17.74 \%$, 35-44 years old were around $35.48 \%, 45-54$ years old were around $22.58 \%$ and over 55 years old were around $24.19 \%$. Around $80 \%$ of the responders were involved in Bachelor study program and the remaining part is involved in Masters study programs. The professors that participated in the study were involved in both study programs.

This study established as main pillars of DL the following aspects: Effectiveness, Interactivity, Feasibility and Perspective of distance learning.

\section{Research Procedure}

The approach uses Mind Genomics, a research procedure which combines messages about a topic, presents these combinations to respondents, obtains responses, and then deconstructs the data to estimate the contribution of each message. In short, Mind Genomics allows the researcher to understand the response of individuals to the granular aspects, the specifics of everyday life (Milutinovic \& Salom, 2016; Moskowitz et al., 2006). Mind Genomics has a 30+ year history, with applications ranging from merchandising (e.g., finding customer requirements for nature food stores (Gere et. al., 2018)), the concerns of people about the prospects of cancer (Gabay et. al., 2018), and even corruption in education (Gere et al., 2019). The Mind Genomics approach is hypothesis-agnostic. Finally, the Mind Genomics approach is statistically oriented. The responses to the vignettes are deconstructed by ordinary least-squares regression (OLS), to reveal the partworth contribution of each element (answer) to the rating question.

Mind Genomics works at the level of the concrete, the granular. The Mind Genomics approach is Socratic (select a topic, select four questions, and for each question provide four alternative answers).

The four 'questions' are actual aspects of DL: Effectiveness, Interactivity, Feasibility and Perspective of distance learning. The Mind Genomics process can be considered as a systematized 'mixing' of ideas. The actual content of the ideas, the 'meaning' and 'implication' of the answer is left to the researcher. The array of "questions" and their associated answers appears in Table 2.

Instead of using a Yes/No question, Mind Genomics creates a scenario by combining answers from different silos without repeating the same scenario twice. The combination of scenarios is referred to as vignette, the respondents provide an evaluation according to their feelings. Feelings are a form of thinking (Kahneman, 2011). Each respondent is presented with 24 different vignettes. A vignette comprises 2-4 elements, at most one element or answer from each question. The 24 combinations are specified by an underlying experimental 
Table 2. The array of "questions" and their associated answers presented in the survey

\begin{tabular}{ll}
\hline Question 1 - How effective is distance learning? \\
\hline A1 & Distance learning is not as effective as the face to face communication \\
A2 & Distance learning is more an individual learning approach \\
A3 & Distance learning platforms are less friendly to use than social media (Facebook, Instagram) \\
A4 & Distance learning is more appropriate for people that have a job \\
\hline Question 2 - How interactive is distance learning? \\
\hline B1 & Distance learning platforms do not favor an immediate feedback from students \\
B2 & Distance learning platforms are not helpful for students during web-seminars \\
B3 & Distance learning platforms allow for interaction between professors and students \\
B4 & Distance learning platforms push students towards rational thinking \\
\hline Question 3 - How feasible is distance learning? \\
\hline C1 & Distance learning platforms require high speed Internet \\
C2 & Distance learning platforms operate with limited supportive infrastructure \\
C3 & Distance learning platforms do provide enough support for labs, seminars and exam sessions \\
C4 & Distance learning platforms provide full support to forums, quizzes, messages, announcements, audio \& video \\
\hline Question 4 - What is the perspective of distance learning as a learning approach? \\
\hline D1 & Distance learning platforms require the ability to upload and download files on and off line \\
D2 & Distance learning platforms should provide interaction as in the classroom \\
D3 & An online tutor is necessary (besides the lecturer) \\
D4 & A better distance learning approach requires more infrastructures and human resources
\end{tabular}

design, dictating the specific content of each vignette. This is the permuted experiment design, which allows a single Mind Genomics experiment to cover a lot of the so-called 'design space' of possible combinations (Gofman \& Moskowitz, 2010; Gofman, 2011).

Summarizing the process, students and professors participating in the survey respond to combined answers into small vignettes using the Likert-type scale from 1 to 9 (1: Unlikely, 9: Likely). The vignettes become little "stories" about distance learning advantages/disadvantages, with the students and the professors alike rating each story. At the start of the Mind Genomics experiment, each individual respondent began the study by first providing information about age, gender, and the reason they use distance learning as follows: Fast learning through tutorial services, Any time and everywhere learning, Learning while working.

A hallmark of this Rule Developing Experimentation (RDE) is the discovery of different patterns of reactions to the elements, patterns which are intuitively obvious and suggest different ways of perceiving the facts of a particular study case; this is referred to as Mind Set. The method, Mind Genomics uses to analyze the data is known as 'clustering,' or 'segmentation' (Mucherino et al., 2009). Segmentation works with the patterns relating the presence/absence of the elements to the actual rating of the 9-point rating scale (Persuasion Model). Clustering uses standard statistical method to discover complementary, homogeneous groups based upon these patterns. These groups show meaningful, radically different patterns, patterns which 'tell different stories.'

Clustering programs can extract two, three, four, five, six and more clusters or segments. The more segments which emerge, the more similar are the patterns within a segment, and the more different are the centroids of the segments. Statistical parsimony and subjective interpretability as the key to the solution: The ideal segmentation is parsimonious (few segments), and interpretable (each segment can be described simply, and makes sense, i.e., tells a story.)

Concretely, Mind Genomics measures the Index of Divergent Thought (Benedek et al., 2014; IDT, Tulving, 1983, 2002). The IDT evaluates the mindsets which in following demonstrate how students and professors react toward the Effectiveness, Interactivity, Feasibility and Perspective of distance learning analyzed aspects. This evaluation method shows how things are going: what works and what does not, related to the matter. 


\section{RESULTS AND DISCUSSIONS}

Results show that $37 \%$ of respondents (the value of intercept) are inclined to use the distance learning in absence of any other information about elements. This is a rather encouraging result. In general, most of students and professors, $49.41 \%$ of them, use distance learning for the reason any time and everywhere learning. This result reinforces the idea that $37 \%$ of respondents are in favor of this learning paradigm in absence of any other information. Next, $27.06 \%$ of respondents use distance learning for Learning through tutorial services. Learning while working is the least appreciated reason, $23.53 \%$.

Results show that based on their statistical relevance the four pillars/groups considered for this study are ordered as follows: The perspective of distance learning as a learning approach is evaluated with the value of 3. The effectiveness pillar is evaluated with the value of 2.75. The interactivity pillar is evaluated with the value of 2.5. And last, the feasibility pillar is evaluated with the value of 0.25 .

Thus, the study shows that as the distance learning approach is taking momentum, the perspective of this paradigm is quite relevant to respondents. The survey results show the more relevant aspects of distance learning from the students and professors point of view. The aspect of perspective of distance learning as a learning approach shows these facts: The element which respondents' value the most (with value of 4) is that the future learning platforms should provide interaction as in the classroom. Students value this item with 2 and all professors older than 35 years old, agree on the matter, they value this item with 6 to 19. Young professors in the group age 25-34 years old do not consider this to be a problem; they value this item with -6 . Males value this item with 6 and are more exigent than females that value this with 4.

The issue of having a vivid interaction between students and professors and among students themselves is very important and central to the education process (Kornbluh, 2020) This collective atmosphere of the class where a simple joke helps distracted students to come again to pay attention to the professor, cannot take place using Zoom or other technology. Teaching and learning is not a simple matter of rote knowledge transmission-experts passing information to non-experts by whatever medium is available (Lossin \& Battle, 2020).

Another issue important to respondents is that a better distance learning approach requires more infrastructures and human resources; this element is evaluated with 3 . In particular students evaluate this with 2 and professors older than 35 years old, agree on the matter and their evaluation goes from 7 to 19. For professors of younger age, 25-34 years old this is not an issue at all, their evaluation is - 13 . Males need more infrastructure and human resources to operate with distance learning platforms; they evaluate this element with 9 while for females there is no need for assistance, they evaluate this element with 1.

The study shows that it is important to respondents that distance learning platforms must have the ability to upload and download files on and off line. Students and professors of the age 45-54 years old agree on the matter by evaluating this element with a high value of 24. Meanwhile professors of age 25-44 do see this element as relevant. Again, males and females evaluate this element differently; males with value 5 and females with value of 1 .

The element that had the highest evaluation from respondents in the study was distance learning platforms push students towards rational thinking evaluated with the value of 5 . Students evaluate this element with a value of 6 and all professors excepting the ones of group age 35 - 44, agree. Professors of age 45-54 evaluate this element with 14. Instead, professors of age 35-44 years old don't think that distance learning platforms push students towards rational thinking. Males evaluate this item very high, with value of 10 and are more favorable than females that evaluate this item with 3 . Regardless of the value, both male and female think that distance learning will push students to be more rationale during their studies.

While in traditional classrooms there is already a social and collective environment between students and professors and among students themselves, the use of distance learning approach changes all parameters of the traditional teaching paradigm. Students were in direct contact with their professor and the professor was mostly guiding the teaching process. The new paradigm moves most of the duties on the student's shoulders, forcing them to be more responsible and resolve many issues related to the learning process by themselves. 
The issue of students becoming more responsible and more rationale as a result of the use of distance learning tools is a topic widely discussed in the literature (Jossberge et al., 2010). Several authors emphasize the relevance of using workplace simulations (WPS) appeal to students' self-directed learning (SDL) and selfregulated learning (SRL) skills, as students are required to work and learn independently in these settings (Tekkol \& Demirel, 2018). As the new learning paradigm is taking a first-hand role in the education process, there is a need to better define the used terminology of self-directed learning (SDL) and self-regulated learning (SRL) skills (Saks \& Leijen, 2014). As the distance learning as the main method for teaching is a new paradigm there is a need to foster innovation, particularly in technology-enhanced learning, at institutional scale (Bennett et al., 2018).

In the pillar of Effectiveness of distance learning the element that was rated with the highest value is Distance learning is more an individual learning approach with a value of 4 . Students evaluated this element with 3 and 35-54 years old professors with an impressive value of 13 . The younger professors of group age 25-34 years old evaluated this element with -8 and older professors of group age over 55 with -3 . These professors do not consider the distance learning as an individual learning approach. Males evaluated this element with 2 and females with 4; both genders agree on this matter but females are more favorable.

In the same pillar, element Distance learning is more appropriate for people that have a job was evaluated with 4. The professors in general evaluated this element with 12 and they are of the opinions that distance learning as an approach is more appropriate for people that have a job. This element is not of any relevance to students as their evaluation is 0 . Males evaluating with a strong 12 are more convinced on this than females evaluating this element with a 1.

The element Distance learning is not as effective as the face to face communication is evaluated with 2. Students have a mild evaluation of 2 while 35-54 years old professors have a strong evaluation of 7 . More convinced on this point result to be the 45-54 years old professors with a strong 9 . Professors of group age 25-34 have a strong negative evaluation of -7 and professors of over 55 years old have an evaluation of -4 . These professors do not consider the face to face communication as more effective than distance learning. Males of an evaluation of 4 are more favorable on this matter than females of an evaluation of 1.

The element Distance learning platforms are less friendly to use than social media (Facebook, Instagram) was ranked with a modest value of 1 . Students do not see any difference between those environments as their evaluation was 0 . Young professors of group age 25-34 years old were strongly against this idea with an -8 and older professors over 55 years old were even negatively stronger with a value of -15 . The $35-54$ years old professors see a big difference between distance learning and social media; a value of 13 . Males see a significant difference in these platforms, a value of 4 in comparison to females of value of -1 .

In the pillar of interactivity of distance learning the element Distance learning platforms allow for interaction between professors and students was overall evaluated with a modest 2. Students were enthusiastic about this idea with a 6 while professors of group age 45-54 were very strong with a 17. Professors of group age 25-34 and 35-44 do not see any interaction, value of -8 and professors over 55 years old professors don 't think that distance learning platforms allow interaction between them and students; their evaluation is -6 . Females (4) are more positive than males (-1).

While evaluating the element Distance learning platforms do not favor an immediate feedback from students the answer overall is very mild, value 2 . Students feel the difference; their evaluation is 4 and 25 34 old professors feel it even stronger with a value of 7. Professors of group age of 45-54 think this issue is very important, with an evaluation of 14 . Professors of age 35-44 and over 55 years old professors confirm that distance learning platforms favor an immediate feedback from students with respective values of -5 and -8. Males (6) have this concern more than females (1). In general terms the feasibility of distance learning is widely accepted from students and professors of both genders.

The Index of Divergent Thoughts (IDT) is also calculated. The divergent thinking typically occurs in a spontaneous, free-flowing manner such that many ideas are generated in an emergent cognitive fashion, and unexpected connections are drawn (Baer, 2014). After the study is completed, using the imagination of Mind 
Genomics ideas the regressions information is organized and structured according to convergent / rational or divergent thinking.

In this study IDT distinguishes two mindsets in approaching distance learning. The first mindset includes students and professors that the mind genomics regression coefficients (IDT) are evaluated 0.18 and the number of responders is 2.256 . While in the second mindset the mind genomics regression coefficients (IDT) are evaluated 0.15 and the number of responders is 1.824 . Correspondingly, the mindset is structured as follows:

- Mindset 1 represents the people that consider important effectiveness and interactivity of distance learning approach, evaluated in average with 8.9.

- Mindset 2 represents the people that consider important the feasibility and perspectives of distance learning approach, evaluated in average with 7.5.

These results also affirm that even though males and females might have opted for different aspects of DL, they both have extensively used it and benefited from the DL approach.

\section{CONCLUSIONS AND RECOMMENDATIONS}

This paper presents a study on distance learning approach; assessed through an online experiment known as Mind Genomics that is used to understand the minds of people. The study shows a structured view based on the perceptions of students and professors that have not experienced distance learning before COVID-19 pandemic period. It is focused on four pillars: feasibility, interactivity, effectiveness and future perspective of the distance learning approach.

The results obtained from this study independently from age group, gender and reasons for, demonstrate that the most significant issues derived from students and professors` distance learning experience are that:

- distance learning platforms push students towards rational thinking;

- distance learning is more appropriate for people that have a job;

- distance learning platforms should provide interaction as in the classroom;

- distance learning is more an individual learning approach.

Meaning, that when these questions are introduced into the vignette at least an additional $4-5 \%$ of the respondents rate positively distance learning approach in addition to the autonomous evaluation of the approach. Any attempts to create new DL tools or to further improve the existing ones, must take into account the abovementioned points.

Rationality is a multifarious concept that encompasses both epistemic (what is true) and instrumental (what to do) thinking. The shift into the rationality in education will enhance the quality of student learning inside and outside of the classroom (Toplak et al., 2012). Seen in the current context, on the one hand the distance learning approach orients the students towards being more demanding about learning and in the other one it becomes more difficult to be accessed from them. This represents a limit almost as distance learning is perceived as more appropriate for people that have a job as well as an individual learning approach. For these reasons, the study results tend to demonstrate that distance learning can be successfully used only as a complementary approach to the traditional one. Another argument is that considering that even in distance learning approach professors' guidance and assistance is crucial in order to help part and full-time students towards rational thinking. Thus, students can use and benefit from distance learning while using it as individual learning approach (referring to reason such as: any time and everywhere learning; learning through tutorial services and learning while working).

In addition, the need to assure the interaction among students and professor as well as among students themselves in distance learning platforms as in traditional classrooms reconfirms the indispensable professors' role play in this approach. This perception reconfirms again that distance learning approach can be successfully used only as a complementary approach to the traditional one. This is valid even when virtual and augmented reality and other high-tech based learning tools are used. Thus, distance learning approach 
could be used in parallel with the traditional one in order to improve the education institutional offer. At first impact it could enrich the traditional classrooms activities, so under professors' guidance for students it can be possible to have a proof of 'dal vivo/live' conferences/experiences from working and research environments. All these activities can be possible with no additional costs for institutions themselves.

Therefore, this study recommends to the higher education institutions that have not experienced distance learning before COVID-19 pandemic period, to start designating ambitious telematic-education strategies which could offer practical options in support of students and professors ' academic activities taking into account the two mindsets. Another recommendation to higher education institutions is that they should provide continuous training sessions for students and professors in order to achieve better practical results while using the DL approach.

\section{ACKNOWLEDGEMENTS}

We thank of all the CEDIMES (Centre d'Etudes sur le Développement International et les Mouvements Economiques et Sociaux) colleagues who helped us in the survey process.

\section{REFERENCES}

Al-Daboubi, A. F. (2014). The Impact of social networking sites on applied science university students. International Journal of Humanities and Social Science, 4(10), 251-267. Retrieved from https://www.ijhssnet.com/journals/Vol_4_No_10_1_August_2014/28.pdf

Alhih, M., Ossiannilsson, E., \& Berigel, M. (2017). Levels of interaction provided by online distance education Models. Eurasia Journal of Mathematics, Science \& Technology Education, 13(6), 2733-2748. https://doi.org/10.12973/eurasia.2017.01250a

Azevedo, R. (2005b). Using hypermedia as a metacognitive tool for enhancing student learning? The role of $\begin{array}{llll}\text { self-regulated learning. Educational } & \text { Psychologist, }\end{array}$ https://doi.org/10.1207/s15326985ep4004_2

Baer, J. (2014). Creativity and divergent thinking: A task-specific approach. Psychology Press.

Baishya, D., \& Maheshwari, S. (2019). WhatsApp Groups in Academic Context: Exploring the Academic Uses of WhatsApp Groups among the Students. Contemporary Educational Technology, 11(1), 55-70. https://doi.org/10.30935/cet.641765

Benedek, M., Jauk, E., Sommer, M., Arendasy, M., \& Neubauer, A. C. (2014). Intelligence, creativity, and cognitive control: The common and differential involvement of executive functions in intelligence and creativity. Intelligence, 46, 73-83. https://doi.org/10.1016/j.intell.2014.05.007

Bennett, S., Lockyer, L., \& Agostinho, Sh. (2018). Towards sustainable technology-enhanced innovation in higher education: Advancing learning design by understanding and supporting teacher design practice. British Journal of Educational Technology, 49(6), 1014-1026. https://doi.org/10.1111/bjet.12683

Birch, D., \& Burnett, B. (2009). Bringing academics on board: encouraging institution-wide diffusion of elearning environments. Australasian Journal of Educational Technology, 25(1), 117-134. https://doi.org/10.14742/ajet.1184

Brown, P. C., Roediger, H. L., \& McDaniel. M. A. (2014). Make it stick: The science of successful learning. Cambridge, MA: Harvard University Press. https://doi.org/10.1080/00220671.2015.1053373

Coymak, A. (2019). An Experimental Study of the Effect of Computer Assisted Learning on Metacognitive Performance Development in Psychology Teaching. Contemporary Educational Technology, 10(1), 94105. https://doi.org/10.30935/cet.512539 
Ertmer, P. A. (2005). Teacher pedagogical beliefs: The final frontier in our quest for technology integration? Educational Technology Research and Development, 53(4), 25-39. https://doi.org/10.1007/BF02504683

Gabay, G., Zemel, R., Gere, A., Zemel, R., Papajorgji, P., \& Moskowitz, H. (2018). On the Threshold: What Concerns Healthy People about the Prospect of Cancer? Cancer Studies and Therapeutics, Research Open, 3(4). Retrieved on 28 March 2020 from https://www.researchgate.net/publication/ 330534911_On_the_Threshold_What_Concerns_Healthy_People_about_the_Prospect_of_Cancer

Gere, A., Papajorgji, P., Moskowitz, H. R., \& Milutinovic, V. (2019). Using a Rule Developing Experimentation Approach to Study Social Problems: The Case of Corruption in Education. International Journal of Political Activism and Engagement (IJPAE), 6(3), 23-48. https://doi.org/10.4018/IJPAE.2019070103

Gere, A., Zemel, R., Papajorgji, P., Sciacca, A., Kaminskaia, J., Onufrey, S., \& Moskowitz, H. (2018). Customer Requirements for Natural Food Stores - The Mind of the Shopper. Nutrition Research and Food Science Journal, 1(1). Retrieved from https://researchopenworld.com/customer-requirements-for-naturalfood-stores-the-mind-of-the-shopper/

Gofman, A. (2011). Rule Developing Experimentation in Consumer-Driven Package Design. https://doi.org/10.1002/9780470400531.eorms1036

Gofman, A., \& Moskowitz, H. (2010). Isomorphic permuted experimental designs and their application in conjoint analysis. Journal of sensory studies, 25(1), 127-145. https://doi.org/10.1111/j.1745459x.2009.00258.x

Grosseck, G., Bran, R., \& Tiru, L. (2011). Dear teacher, what should I write on my wall? A case study on academic uses of Facebook. Procedia Social and Behavioral Sciences, 15, 1425-1430. https://doi:10.1016/j.sbspro.2011.03.306

Gutierrez - Santuste, E. Gallego - Arrufat, M.G. \& Simone, A. 2016. Barriers in computer-mediated communication: typology and evolution over time. Journal of E-learning and Knowledge Management, 12(1),107-119. https://doi.org/10.20368/1971-8829/953

Hart, J. (2014). Social learning handbook 2014. Centre for Learning \& Performance Technologies.

Jariang Pcasert, N. (2003). The opinion of faculty of business administration lectures and students ,Chiang Mai University about the use of E- Learning. Songklanakarin J of Social Sciences \& Humanities, 9(2), 136-145.

Jossberger, H., Brand-Gruwel, S., Boshuizen, H., \& Van De Wiel, M. (2010). The challenge of self-directed and self-regulated learning in vocational education: A theoretical analysis and synthesis of requirements. Journal of Vocational Education and Training, 62(4), 415-440. http://doi.org/10.1080/13636820.2010.523479

Kahneman, D. (2011). Thinking, fast and slow. Macmillan.

Koehler, M., \& Mishra, P. (2009). What is technological pedagogical content knowledge (TPACK)?. Contemporary issues in technology and teacher education, 9(1), 60-70. Retrieved from https://tecfalabs.unige.ch/mitic/articles/koehler_mishra_2009_what_is_technological_pedagogical_ content_knowledge.pdf

Kornbluh, A. (2020). Academe's Coronavirus Shock Doctrine. In: The Chronicle of Higher Education, 12. Retrieved from https://www.chronicle.com/article/Academe-s-Coronavirus-Shock/248238

Litchfield, A., Dyson, L. E., Lawrence, E., \& Zmijewska, A. (2007). Directions for m-learning research to enhance active learning. ASCILITE 2007-The Australasian Society for Computers in Learning in Tertiary Education, 587-596. Retrieved from https://www.ascilite.org/conferences/singapore07/procs/litchfield.pdf 
Lossin, R. H., \& Battle, A. (2020). Resisting Distance Learning. In: Higher Education in the Age of Coronavirus. Retrieved from_http://bostonreview.net

Milutinovic, V., \& Salom, J. (2016). Mind Genomics: A Guide to Data-Driven Marketing Strategy. Springer.

Mohamed, K., \& Sumitha, E. (2011). Perception and use of Social Networking Sites by the students of Calicut University. DESIDOC Journal of Library and Information Technology, 31(4), 295-301. https://doi.org/10.14429/djlit.31.4.1109

Moro, C., Štromberga, Z., Raikos, A., \& Stirling, A. (2017). The effectiveness of virtual and augmented reality in health sciences and medical anatomy. Anatomical sciences education, 10(6), 549-559. https://doi.org/10.1002/ase.1696

Moskowitz, H. R., Gofman, A., Beckley, J., \& Ashman, H. (2006). Founding a new science: Mind genomics. Journal of sensory studies, 21(3), 266-307. https://doi.org/10.1111/j.1745-459X.2004.00066.x

Mucherino, A., Papajorgji, P., \& Pardalos, P. M. (2009). Data mining in agriculture (Vol. 34). Springer Science \& Business Media. https://doi.org/10.1007/978-0-387-88615-2

Nedelman, C.A. (2013). Exploring organizational and cultural barriers to developing distance learning programs in higher education (PhD Thesis). North Central University. Retrieved from https://search.proquest.com/openview/a004ead5846591dd5dd3f25594cb090c/1?pqorigsite $=$ gscholar $\&$ cbl=18750\&diss $=y$

Online Learning Statistics. (2019). Retrieved on 3 April 2020 from https://skillscouter.com/online-learningstatistics/

Ossiannilsson, E. (2012). Benchmarking e-learning in higher education: lessons learned from international projects. Juvenes Print.

Ossiannilsson, E., Williams, K., Camilleri, A. F., \& Brown, M. (2015). Quality models in online and open education around the globe. State of the art and recommendations. Oslo: International Council for Open and Distance Education. Retrieved from https://www.pedocs.de/volltexte/2015/10879/pdf/Ossiannilsson_et_al_2015_Qualitymodels.pdf

Robinson, K. (2009). The element: How finding your passion changes everything. Penguin.

Ruleman, A. B. (2012). Social media at the university: A demographic comparison. New Library World, 113(7/8), 316-332. https://doi.org/10.1108/03074801211244940

Saks, K., \& Ä. Leijen, Ä. (2014). Distinguishing Self-Directed and Self-Regulated Learning and Measuring them in the E-learning Context. Procedia - Social and Behavioral Sciences, 112, 190-198. http://doi.org/10.1016/j.sbspro.2014.01.1155

Saulo, A. A., Moskowitz, H. R., Gere, A., Papajorgji, P., Ettinger Lieberman, L., \& Feuerwerker, D. (2019). Linking Food Endorsement Labels \& Messaging to Perceived Price and Emotions. A Mind Genomics ${ }^{\circledR}$ Exploration. Advances in Nutrition and Food Science, ANAFS-152. Retrieved from https://kosmospublishers.com/linking-food-endorsement-labels-messaging-to-perceived-price-andemotions-a-mind-genomics-exploration/

Schmidt, D., Baran, E., \& Thompson, A. (2009). Technological pedagogical content knowledge (TPACK): the development and validation of an assessment instrument for preservice teachers. Journal of Research on Technology in Education, 42(3), 123-149. https://doi.org/10.1080/15391523.2009.10782544

Schwarz, B. B., \& Asterhan, C. S. (2011). E-moderation of synchronous discussions in educational settings: A nascent practice. Journal of the Learning Sciences, 20(3), 395-442. https://doi.org/10.1080/10508406.2011.553257

Simonson, M., \& Schlosser, L. A. (2009). Distance Education 3rd Edition: Definition and Glossary of Terms. IAP. 
Sun, P. C., Tsai, R. J., Finger, G., Chen, Y. Y., \& Yeh, D. (2007). What drives a successful e-Learning? An empirical investigation of the critical factors influencing learner satisfaction. Computers \& education, 50(4), 1183-1202. https://doi.org/10.1016/j.compedu.2006.11.007

Tekkol, i. A., \& Demirel, M. (2018). An investigation of self-directed learning skills of undergraduate students. Frontiers in psychology, 9, 2324. https://doi.org/10.3389/fpsyg.2018.02324.

Toplak, M. E., West, R. F., \& Stanovich, K. E. (2012). Education for rational thought. In J. R. Kirby \& M. J. Lawson (Eds.), Enhancing the quality of learning: Dispositions, instruction, and learning processes ( $\mathrm{p}$. 51-92). Cambridge University Press. https://doi.org/10.1017/СBO9781139048224.006

Tulving, E. (1983). Ecphoric processes in episodic memory. Philosophical Transactions of the Royal Society of London. B, Biological Sciences, 302(1110), 361-371. https://doi.org/10.1098/rstb.1983.0060

Tulving, E. (2002). Episodic memory: From mind to brain. Annual review of psychology, 53(1), 1-25. https://doi//10.1146/annurev.psych.53.100901.135114

Zemel, R., Choudhuri, S. G., Gere, A., Upreti, H., Deite, Y., Papajorgji, P., \& Moskowitz, H. (2019). Mind, Consumers, and Dairy: Applying Artificial Intelligence, Mind Genomics, and Predictive Viewpoint Typing. In Current Issues and Challenges in the Dairy Industry. IntechOpen. https://doi.org/10.5772/intecopen.85532

Correspondence: Ardita Todri, Faculty of Economics, University of Elbasan "Aleksandër Xhuvani”, Albania. Email: ardita.todri@gmail.com 